\title{
DINÂMICA DA COBERTURA DO SOLO POR PLANTAS E NDVI DE CULTIVARES DE SOJA EM DIFERENTES ARRANJOS ESPACIAIS DE PLANTAS
}

\author{
Flávia Werner ${ }^{1}$, Marcelo Augusto de Aguiar e Silva ${ }^{1}$, André Sampaio Ferreira ${ }^{1}$, Norman Neumaier ${ }^{2}$, Alvadi \\ Antonio Balbinot Junior ${ }^{2}$ \\ ${ }^{1}$ Universidade Estadual de Londrina - UEL, Londrina, PR. ${ }^{2}$ Empresa Brasileira de Pesquisa Agropecuária - EMBRAPA \\ Soja. E-mail: flawerner6@gmail.com
}

\section{RESUMO}

O objetivo do trabalho foi avaliar a dinâmica da cobertura do solo por plantas e NDVI de duas cultivares de soja com tipo de crescimento indeterminado, em diferentes arranjos espaciais de plantas, compostos por espaçamentos entre fileiras e densidades de semeadura. O experimento foi conduzido nas safras 2013/14 e 2014/15 com delineamento experimental em blocos completos casualizados, esquema fatorial $2 \times 4 \times 3$, com três repetições. Os tratamentos constituíram-se da combinação de duas cultivares: BRS 359 RR e BMX Potência RR, de quatro espaçamentos entre fileiras: $20 \mathrm{~cm}$ (reduzido); 20/80 cm (fileira dupla); $50 \mathrm{~cm}$

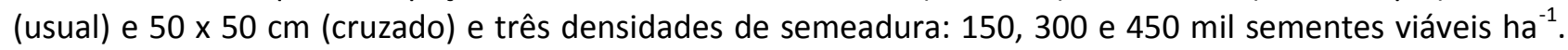
Foram avaliados o índice de vegetação por diferença normalizada (NDVI) e a porcentagem da cobertura do solo pelo dossel. O NDVI e a porcentagem de cobertura do solo pelo dossel de cultivares modernas de soja, com tipo de crescimento indeterminado, são mais afetados pelos espaçamentos entre fileiras no início do ciclo de desenvolvimento, mas na fase de enchimento de grãos as diferenças são menores. A densidade de 150 mil sementes viáveis ha ${ }^{-1}$ ocasiona menor NDVI e cobertura do dossel no início do ciclo, entretanto no final do ciclo essa diferença se dissipa e todas as densidades apresentam pleno fechamento do dossel. Palavras-chave: densidade de semeadura; espaçamentos entre fileiras; Glycine max L.; NDVI; tipo de crescimento indeterminado.

\section{DYNAMICS OF SOIL COVERAGE BY PLANTS AND NDVI OF SOYBEAN CULTIVARS IN DIFFERENT PLANT ARRANGEMENTS}

\begin{abstract}
The aim of this work was to evaluate the dynamics of soil coverage by plants and NDVI in two soybean cultivars of indeterminate growth type in different spatial plant arrangement, composed by different row spacing and seeding rates. The experiment was conducted in 2013/14 and 2014/15 growing seasons in a randomized complete block design, with the treatments in a $2 \times 4 \times 3$ factorial arrangement, and with three replications. The treatments consisted of the combination of two soybean cultivars: BRS 359 RR and BMX Potência RR, four row spacings: $20 \mathrm{~cm}$ (reduced); 20/80 cm (twin row); $50 \mathrm{~cm}$ (standard) and $50 \times 50 \mathrm{~cm}$ (crossed lines) and three seeding rates (150, 300 and 450 thousand viable seeds ha ${ }^{-1}$ ). Were evaluated the Normalized Difference Vegetation Index (NDVI) and the percentage of ground cover by canopy. The NDVI and the percentage of soil covered by the canopy of modern soybean cultivars of indeterminate growth type, are most affected by the row spacing at the beginning of the development cycle, but in the grain filling stage the differences disappear. The density of 150 thousand viable seeds ha ${ }^{-1}$ leads to lower NDVI and canopy cover early in the cycle, however at the end of the cycle this difference vanishes and all densities have full canopy closure.

Keywords: Glycine max L.; indeterminate growth habit; NDVI; row spacing; seeding rate.
\end{abstract}

\section{INTRODUÇÃO}

Alterando o espaçamento entre as fileiras e a densidade de semeadura as características estruturais da planta são modificadas, influenciando na velocidade de fechamento entre as fileiras, na formação de biomassa e na 
cobertura do solo pelas plantas (HEIFFIG et al., 2006, SILVA et al., 2013) e podendo potencializar a produtividade de grãos (BALBINOT JUNIOR et al., 2015a,b). Entretanto, há poucos trabalhos com arranjo de plantas considerando a introdução dessas novas cultivares que apresentam como atributos tipo de crescimento indeterminado, ciclo de desenvolvimento precoce e arquitetura compacta, que são características cada vez mais desejadas em programas de melhoramento genético de soja (PROCÓPIO et al., 2013).

Dispõe-se de várias formas para se estimar o crescimento das plantas, como a massa seca, área foliar, altura de plantas, os índices de vegetação e porcentagem de cobertura do solo que monitoram e estimam as mudanças na biomassa e no desenvolvimento vegetal (BALBINOT JUNIOR et al., 2016, WERNER et al., 2016). O perfil temporal do Índice de Vegetação por Diferença Normalizada (NDVI) pode ser empregado para detectar variações na fenologia das culturas, duração do período de crescimento, pico de verde, modificações fisiológicas das folhas e períodos de senescência (PONZONI et al., 2012).

O NDVI detecta a presença de clorofila e outros pigmentos responsáveis pela absorção da radiação solar na banda do vermelho (HUETE et al., 2002), consistindo no cálculo da diferença entre emissão e reflexão de dois comprimentos de onda do espectro eletromagnético: infravermelho próximo $(0,725-1,1 \mu \mathrm{m})$ e vermelho $(0,58-0,68 \mu \mathrm{m})$, e seu valor varia de -1 a 1, de acordo com a fórmula: NDVI= (pivp$\rho v) /(\rho i v \rho+\rho v)$, onde pivp é a refletância no infravermelho próximo e $\rho v$ é a refletância no vermelho. À medida que o verde se intensifica e a cobertura vegetal se amplia o NDVI aumenta (RAMME et al., 2010). Diante do exposto o objetivo do trabalho foi avaliar a dinâmica da cobertura do solo por plantas e NDVI de duas cultivares de soja de tipo de crescimento indeterminado, em diferentes arranjos espaciais de plantas, compostos por diferentes espaçamentos entre fileiras e densidades de semeadura.

\section{MATERIAL E MÉTODOS}

O experimento foi realizado nas safras 2013/14 e 2014/15, na Fazenda Experimental da Embrapa Soja, em Londrina, PR (2311' S, $51^{\circ} 11^{\prime} \mathrm{W}$ e altitude de $\left.620 \mathrm{~m}\right)$, utilizando a mesma área experimental. 0 solo foi classificado como Latossolo Vermelho distroférrico e apresentava os seguintes atributos, na camada de 0 a $20 \mathrm{~cm}$, antes da implantação dos experimentos: $21,4 \mathrm{~g} \mathrm{dm}^{-3}$ de matéria orgânica; 4,9 de $\mathrm{pH}$ em $\mathrm{CaCl}_{2} ; 8,6 \mathrm{mg} \mathrm{dm}^{-3}$ de $\mathrm{P} ; 0,55 \mathrm{cmol}_{\mathrm{c}}$ $\mathrm{dm}^{-3}$ de K; $3,7 \mathrm{cmol}_{\mathrm{c}} \mathrm{dm}^{-3}$ de Ca; $1,4 \mathrm{cmol}_{\mathrm{c}} \mathrm{dm}^{-3}$ de $\mathrm{Mg}$; e 55\% de saturação da CTC por bases.

A cobertura vegetal presente na área experimental foi manejada mecanicamente aos onze dias antes da semeadura da soja em ambas as safras, utilizando-se um triturador de restos culturais (triton). Nove dias após essa operação, a vegetação remanescente foi dessecada quimicamente com glyphosate (1.080 g i.a.ha $\left.{ }^{-1}\right)$ e carfentrazone-ethyl (30 g i.a. ha $\left.{ }^{-1}\right)$. A semeadura da soja foi realizada em sistema plantio direto, em 30/10/2013, sobre palha de trigo, e em $12 / 11 / 2014$, sobre palha de aveia-preta. As sementes foram tratadas com Carboxina $(30 \mathrm{ml}$ i.a $50 \mathrm{~kg}^{-1}$ de sementes) e Tiram ( $30 \mathrm{ml}$ i.a $50 \mathrm{~kg}^{-1}$ de sementes) e inoculadas com Bradyrhizobium elkanii na concentração de $5 \times 10^{9} \mathrm{UFC} \mathrm{ml}^{-1}$ (100 $\mathrm{ml} 50 \mathrm{~kg}^{-1}$ de sementes).

A adubação de base constitui-se da aplicação de $350 \mathrm{~kg} \mathrm{ha}^{-1}$ de superfosfato simples e $250 \mathrm{~kg} \mathrm{ha}^{-1}$ de cloreto de potássio na safra 2013/14 e $122 \mathrm{~kg} \mathrm{ha}^{-1}$ de superfosfato triplo e $250 \mathrm{~kg} \mathrm{ha}^{-1}$ de cloreto de potássio na safra 2014/15, aplicados a lanço 10 dias antes da semeadura. $O$ controle de doenças, insetos-praga e plantas daninhas foi efetuado conforme as indicações técnicas preconizadas para a cultura da soja. As cultivares de soja utilizadas foram a BMX Potência RR e BRS 359 RR, ambas com tipo de crescimento indeterminado e grupo de maturidade relativa 6.7 e 6.0 , respectivamente. 0 delineamento experimental foi em blocos completos casualizados, em esquema fatorial $2 \mathrm{x}$ $4 \times 3$, com três repetições. Os tratamentos foram formados pela combinação de duas cultivares: BRS 359 RR e BMX Potência RR, quatro espaçamentos entre fileiras: $20 \mathrm{~cm}$ (reduzido); 20/80 cm (fileira dupla); $50 \mathrm{~cm}$ (usual) e $50 \times 50$ $\mathrm{cm}$ (cruzado) e três densidades de semeadura $\left(150,300\right.$ e 450 mil sementes viáveis ha $\left.{ }^{-1}\right)$. As parcelas mediam 10,0 m de comprimento e 5,0 m de largura, totalizando $50,0 \mathrm{~m}^{2}$, sendo sua área útil de $15,0 \mathrm{~m}^{2}$ (10,0 $\mathrm{m}$ de comprimento por 1,5 $\mathrm{m}$ de largura). Para ambas as safras foram avaliados o Índice de Vegetação por Diferença Normalizada (NDVI) e a porcentagem da cobertura do solo pelo dossel.

Para estimar o fechamento das entrelinhas foi utilizado o aparelho Green 
Seeker $^{\circledast} 505$ Handheld Sensor, que possui dimensões de $35,5 \times 129,5 \mathrm{~cm}$, portátil e equipado com um sensor ativo e não imageador capaz de calcular o NDVI. As leituras foram realizadas com horário padronizado às 13 horas a uma altura de $90 \mathrm{~cm}$ acima do topo do dossel. Foram realizadas para a safra 2013/2014 cinco avaliações aos $27,35,43,49$ e 82 dias após a semeadura (DAS) (estádios V3, V4, V5, V6 para as duas cultivares; R3 para a cultivar BMX Potência RR e R4 para a cultivar BRS 359 RR) e para safra de 2014/2015 foram realizadas três avaliações aos 33, 57 e 91 DAS (estádios V4 para as duas cultivares; R1 e R4 para a cultivar BMX Potência RR e R2 e R5 para a cultivar BRS 359 RR).

Para a avaliação da cobertura do solo pelo dossel foram utilizadas imagens obtidas por uma câmara fotográfica digital (Sony DSC-H9) direcionada verticalmente para baixo, acoplada a um aparato que consistia de um perfilado de seção retangular $(2,5 \mathrm{~cm} \times 5,0 \mathrm{~cm}) \mathrm{em}$ duralumínio com $2,3 \mathrm{~m}$ de altura, e braço horizontal de $1,5 \mathrm{~m}$, cruzando-se num ângulo reto a $20 \mathrm{~cm}$, ficando o comprimento útil do braço em 1,3 $\mathrm{m}$ e altura útil em 2,1 m. Em cada parcela foi selecionado um único local em todas as avaliações para o posicionamento da haste vertical do aparato. As fotos foram analisadas com o auxílio do software Siscob ${ }^{\circledR}$, desenvolvido pela Embrapa Instrumentação Agropecuária. Foram realizadas para a safra 2013/2014 quatro avaliações aos 27, 35, 43 e 49 dias após a semeadura (DAS) e para safra de 2014/2015 foram realizadas duas avaliações aos 33 e 57 DAS.

Os dados obtidos foram analisados quanto à normalidade dos resíduos e homocedasticidade das variâncias dos tratamentos, utilizando-se os testes de ShapiroWilk e de Cochran, respectivamente, os quais indicaram não ser necessária a transformação dos dados. Posteriormente, os dados foram submetidos à análise de variância, sendo os efeitos do fator cultivar comparados pelo teste $F$ e as médias dos demais fatores comparadas pelo teste de Tukey com $(p \leq 0,05)$ separadamente para cada safra de cultivo. Também foi realizada análise de correlação linear de Pearson entre o NDVI e a porcentagem de cobertura do solo pelo dossel.

\section{RESULTADOS E DISCUSSÃO}

Não houve interação tripla entre os fatores estudados (cultivares $x$ densidades $x$ espaçamentos) para todas as variáveis avaliadas, nas duas safras. $\mathrm{Na}$ safra 2013/2014, observou-se interação entre espaçamentos e densidades para o Índice de Vegetação por Diferença Normalizada (NDVI) aos 27 DAS. O espaçamento reduzido $(20 \mathrm{~cm})$ nas densidades de 300 e 450 mil sementes viáveis ha ${ }^{-1}$ apresentou os menores valores de NDVI (Tabela 1 ), devido ao maior espaço entre as plantas na linha de semeadura. Em todos os espaçamentos, as menores densidades (150 e 300 mil sementes viáveis ha ${ }^{-1}$ ) apresentaram menores valores de NDVI por possuírem menor quantidade total de plantas nas parcelas, resultando assim em maior refletância do vermelho e, consequentemente, menores valores de NDVI (RAMME et al., 2010). Houve interação entre espaçamentos e densidades para o NDVI aos 33 DAS, em que a densidade de 150 mil sementes viáveis ha ${ }^{-1}$ em todos os espaçamentos avaliados obteve os menores valores de NDVI (Tabela 1). Isso decorreu em razão da menor quantidade de plantas na área e, estas, por serem menores, não conseguiram cobrir o solo e, consequentemente, atingir maiores valores de NDVI.

Na safra 2014/2015 na densidade de 300 mil sementes viáveis ha $^{-1}$, o espaçamento em fileira dupla $(20 / 80 \mathrm{~cm})$ proporcionou o maior NDVI, devido a maior quantidade de plantas na linha de semeadura. $\mathrm{O}$ maior índice de fechamento pode auxiliar no controle das plantas daninhas e na interceptação da radiação fotossinteticamente ativa (RFA). Entretanto, índices precoces de fechamento podem acarretar autossombreamento das folhas do terço inferior e redução da circulação de ar, ocasionando desse modo menor eficiência no uso da RFA e microclima favorável ao desenvolvimento de algumas doenças (SILVA et al., 2013). 
Tabela 1. Índice de Vegetação por Diferença Normalizada (NDVI) aos 27 e 35 dias após a semeadura (DAS) (safra 2013/2014) e aos 33 DAS (safra 2014/2015), em diferentes espaçamentos entre fileiras, densidades de semeadura e cultivares de soja. Londrina-PR.

\begin{tabular}{|c|c|c|c|c|}
\hline \multirow{3}{*}{$\begin{array}{c}\text { Densidade } \\
\left(\text { mil sementes viáveis } \mathrm{ha}^{-1}\right)\end{array}$} & \multicolumn{4}{|c|}{ Espaçamentos $(\mathrm{cm})$} \\
\hline & 20 & $20 / 80$ & 50 & $50 \times 50$ \\
\hline & \multicolumn{4}{|c|}{27 DAS } \\
\hline 150 & $0,22 \mathrm{Ba}^{1}$ & $0,26 \mathrm{Ca}$ & $0,25 \mathrm{Ca}$ & $0,28 \mathrm{Ca}$ \\
\hline 300 & $0,27 \mathrm{ABb}$ & $0,35 \mathrm{Ba}$ & $0,35 \mathrm{Ba}$ & $0,35 \mathrm{Ba}$ \\
\hline 450 & $0,31 \mathrm{Ab}$ & $0,44 \mathrm{Aa}$ & $0,42 \mathrm{Aa}$ & $0,41 \mathrm{Aa}$ \\
\hline $\mathrm{CV}(\%)$ & \multicolumn{4}{|c|}{10,6} \\
\hline Cultivares & \multicolumn{4}{|c|}{27 DAS } \\
\hline BRS 359 RR & $0,26 A b^{1}$ & $0,36 \mathrm{Aa}$ & $0,37 \mathrm{Aa}$ & $0,35 \mathrm{Aa}$ \\
\hline BMX Potência RR & $0,27 \mathrm{Ab}$ & $0,34 \mathrm{Aa}$ & 0,31 Bab & $0,35 \mathrm{Aa}$ \\
\hline \multirow[t]{2}{*}{$\mathrm{CV}(\%)$} & \multicolumn{4}{|c|}{10,6} \\
\hline & \multicolumn{4}{|c|}{35 DAS } \\
\hline BRS 359 RR & $0,37 \mathrm{Ab}$ & $0,44 \mathrm{Aab}$ & $0,49 \mathrm{Aa}$ & $0,48 \mathrm{Aa}$ \\
\hline BMX Potência RR & $0,41 \mathrm{Aa}$ & $0,44 \mathrm{Aa}$ & $0,41 \mathrm{Ba}$ & $0,46 \mathrm{Aa}$ \\
\hline $\mathrm{CV}(\%)$ & \multicolumn{4}{|c|}{12,4} \\
\hline Densidade & \multirow{2}{*}{\multicolumn{4}{|c|}{33 DAS }} \\
\hline$\left(\right.$ mil sementes viáveis ha ${ }^{-1}$ ) & & & & \\
\hline 150 & $0,30 \mathrm{Ca}$ & $0,32 \mathrm{Ba}$ & $0,29 \mathrm{Ba}$ & $0,28 \mathrm{Ba}$ \\
\hline 300 & $0,40 \mathrm{Bb}$ & $0,48 \mathrm{Aa}$ & $0,32 \mathrm{Bb}$ & $0,38 \mathrm{Ab}$ \\
\hline 450 & $0,52 \mathrm{Aa}$ & $0,50 \mathrm{Aa}$ & $0,50 \mathrm{Aa}$ & $0,45 \mathrm{Aa}$ \\
\hline$C V(\%)$ & \multicolumn{4}{|c|}{13,9} \\
\hline
\end{tabular}

${ }^{1}$ Médias seguidas pelas mesmas letras, minúsculas na linha e maiúsculas na coluna, não diferem entre si pelo teste de Tukey, $(p \leq 0,05)$.

Houve interação entre espaçamentos e cultivares para o NDVI aos 27 e 35 DAS na safra 2013/14. O NDVI aos 27 DAS foi menor no espaçamento de $20 \mathrm{~cm}$ para ambas as cultivares (Tabela 1), isso se deve a menor quantidade de plantas na linha de semeadura. Aos 35 DAS, somente a cultivar BRS 359 RR no espaçamento reduzido (20 $\mathrm{cm})$ e em fileira dupla (20/80) apresentaram menores NDVIs. Entre as cultivares somente houve diferença no espaçamento usual $(50 \mathrm{~cm})$, em que a cultivar BRS 359 RR apresentou maior NDVI aos 27 e 35 DAS, devido a esta possuir um ciclo mais curto em relação a cultivar BMX Potência RR. Mesmo com a utilização de cultivares com tipo de crescimento indeterminado, ciclo curto e arquitetura compacta de plantas, verificou-se o efeito da compensação dos espaços vazios pelo maior crescimento de cada indivíduo na área (PROCÓPIO et al., 2013).

O NDVI em todas as avaliações para a safra 2013/14 apresentou efeito isolado de densidade de semeadura, sendo o NDVI aos 27, 35, 43 e 49 DAS maior para a densidade de 450 mil sementes viáveis ha $^{-1}$ (Tabela 2). No entanto, aos 82 DAS, as densidades de semeadura avaliadas não diferiram quanto ao valor de NDVI, demonstrando a alta plasticidade fenotípica da cultura da soja. Dos estádios iniciais da cultura, houve incremento da biomassa verde, o qual foi acompanhado por aumento dos valores de NDVI. Segundo Rodrigues et al. (2013) o valor máximo de NDVI é alcançado quando a cultura apresenta o máximo índice de área foliar. 
Tabela 2. Índice de Vegetação por Diferença Normalizada (NDVI) aos 27, 35, 43, 49 e 82 dias após a semeadura (DAS) (safra 2013/14) e aos 33, 57 e 91 DAS (safra 2014/15), em diferentes densidades de semeadura (médias de duas cultivares e quatro espaçamentos entre fileiras) e em diferentes espaçamentos entre fileiras (médias de duas cultivares e três densidades de semeadura). Londrina-PR

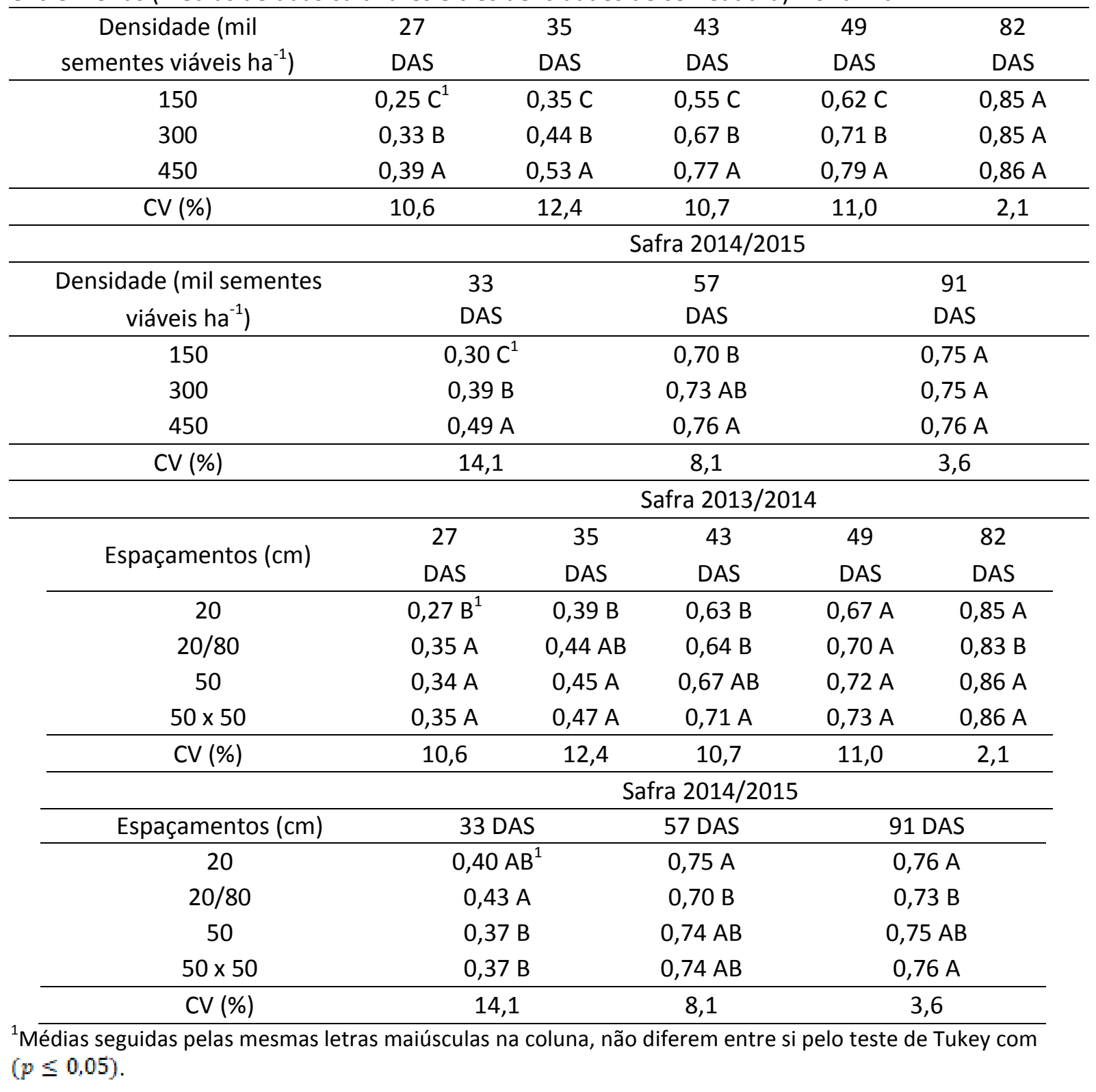

Na safra 2014/15, o efeito da densidade de semeadura sobre o NDVI foi significativo em todas as avaliações realizadas. Aos 33 DAS houve um acentuado decréscimo do NDVI à medida que a densidade de semeadura diminuiu. Aos 57 DAS, este efeito foi semelhante, porém menos drástico, e apenas os NDVIs da maior e da menor densidade de semeadura diferiram significativamente (Tabela 2). Entretanto, aos 91 DAS as densidades de semeadura avaliadas não diferiram entre si, assim como na safra 2013/14 (Tabela 2), demonstrando a alta plasticidade fenotípica da soja. Isso indica que, com o avanço do ciclo da cultura, as plantas apresentaram características de alta plasticidade, ou seja, capacidade de se adaptar às condições ambientais e de manejo, por meio de modificações na morfologia, sobretudo emitindo mais ramos e ramos maiores em baixas densidades de plantas (HOLTZ et al., 2014).

Houve efeito isolado de espaçamento para o NDVI em todas as avaliações para a safra 2013/14 sendo que, no início do desenvolvimento da cultura o NDVI foi menor para os espaçamentos reduzido $(20 \mathrm{~cm})$ e fileira dupla $(20 / 80 \mathrm{~cm})$ (Tabela 2), devido à disposição das plantas na área. No espaçamento reduzido há menor quantidade de plantas na linha de semeadura e para o espaçamento em fileira dupla há um espaço maior entre as linhas de semeadura, ocasionando assim menores valores de NDVI. Já, aos 82 DAS, o NDVI 
foi menor somente para o espaçamento fileira dupla $(20 / 80 \mathrm{~cm})$. Isso ocorreu devido à distância entre uma fileira dupla e a fileira dupla adjacente ser maior que nos outros tratamentos, pois, apesar da cultura da soja apresentar alta plasticidade fenotípica, não conseguiu ocupar o espaço entre elas.

Houve efeito isolado de espaçamentos para o NDVI na safra 2014/15 em todas as avaliações. Os espaçamentos em fileira dupla e usual apresentaram os menores valores de NDVI aos 57 e 91 DAS (Tabela 2), causado pela maior distância entre as linhas de semeadura. Para todos os outros espaçamentos avaliados aos 91 DAS não houve diferença entre os valores de NDVI em razão da melhor distribuição das plantas na área o que ocasionou a menor refletância do vermelho e consequentemente maiores valores de NDVI. Resultados semelhantes foram obtidos por Holtz et al. (2014) em que os espaçamentos de 30, 40, 50 e
$50 \times 50 \mathrm{~cm}$ (cruzado) obtiveram o fechamento do dossel e os maiores espaçamentos (60 e $70 \mathrm{~cm}$ ) não conseguiram fechar o dossel, assim como entre as fileiras duplas $(20 / 80 \mathrm{~cm})$ no presente estudo.

A porcentagem da cobertura do solo pelo dossel em todas as avaliações na safra 2013/14 apresentou efeito isolado de densidade de semeadura. Em todas as avaliações, a maior densidade de semeadura (450 mil sementes viáveis $\mathrm{ha}^{-1}$ ) apresentou o maior valor de porcentagem de cobertura do solo pelo dossel (Tabela 3), em função da maior quantidade de plantas na área, ocasionando também a maior cobertura da área pelas plantas. Heiffig et al. (2006) observaram que a população de 350 mil plantas ha ${ }^{-1}$ obteve o menor tempo de fechamento nas entrelinhas em relação as populações de 70, 140, 210 e 280 mil plantas ha ${ }^{-1}$.

Tabela 3. Porcentagem da cobertura do solo pelo dossel aos $27,35,43$ e 49 dias após a semeadura (DAS) (safra 2013/14) e aos 33 e 57 DAS (safra 2014/15), em diferentes densidades de semeadura (médias de duas cultivares e quatro espaçamentos entre fileiras) e em diferentes espaçamentos entre fileiras (médias de duas cultivares e três densidades de semeadura). Londrina-PR

\begin{tabular}{|c|c|c|c|c|c|c|}
\hline \multirow{3}{*}{ Densidade $^{1}$} & \multicolumn{4}{|c|}{ Safra 2013/14 } & \multicolumn{2}{|c|}{ Safra 2014/15 } \\
\hline & 27 & 35 & 43 & 49 & 33 & 57 \\
\hline & DAS & DAS & DAS & DAS & DAS & DAS \\
\hline 150 & $7,71 C^{2}$ & $18,60 \mathrm{C}$ & $39,51 \mathrm{C}$ & $52,44 \mathrm{C}$ & $16,3 \mathrm{C}$ & $79,1 \mathrm{~B}$ \\
\hline 300 & $14,71 \mathrm{~B}$ & $32,00 \mathrm{~B}$ & 61,27 B & 69,84 B & $27,1 \mathrm{~B}$ & $89,8 \mathrm{~A}$ \\
\hline 450 & $22,17 \mathrm{~A}$ & $42,14 \mathrm{~A}$ & $73,78 \mathrm{~A}$ & $81,16 \mathrm{~A}$ & $39,4 \mathrm{~A}$ & $91,1 \mathrm{~A}$ \\
\hline \multirow[t]{2}{*}{ CV (\%) } & 22,0 & 22,0 & 16,3 & 14,3 & 20,7 & 9,9 \\
\hline & \multicolumn{4}{|c|}{ Safra 2013/14 } & \multicolumn{2}{|c|}{ Safra 2014/15 } \\
\hline \multirow[t]{2}{*}{ Espaçamentos $(\mathrm{cm})$} & 27 & 35 & 43 & 49 & 33 & 57 \\
\hline & DAS & DAS & DAS & DAS & DAS & DAS \\
\hline 20 & $12,75 \mathrm{~B}^{1}$ & $28,2 \mathrm{~B}$ & $58,27 \mathrm{~B}$ & $66,8 \mathrm{~B}$ & $36,5 \mathrm{~A}$ & $92,8 \mathrm{~A}$ \\
\hline $20 / 80$ & $12,73 \mathrm{~B}$ & $25,7 \mathrm{~B}$ & $44,09 \mathrm{C}$ & $55,3 \mathrm{C}$ & $20,6 \mathrm{C}$ & $73,3 \mathrm{~B}$ \\
\hline 50 & $16,04 \mathrm{~A}$ & $34,4 \mathrm{~A}$ & $62,0 \mathrm{AB}$ & $71,0 \mathrm{AB}$ & $26,1 \mathrm{~B}$ & $90,7 \mathrm{~A}$ \\
\hline $50 \times 50$ & $17,93 \mathrm{~A}$ & $35,3 \mathrm{~A}$ & $68,4 \mathrm{~A}$ & $78,2 \mathrm{~A}$ & $27,1 \mathrm{~B}$ & $89,8 \mathrm{~A}$ \\
\hline CV (\%) & 22,0 & 22,0 & 16,3 & 14,3 & 20,7 & 9,9 \\
\hline
\end{tabular}

${ }^{1} \mathrm{Mil}$ sementes viáveis $\mathrm{ha}^{-1}{ }^{2}{ }^{2}$ Médias seguidas pelas mesmas letras maiúsculas na coluna, não diferem entre si pelo teste de Tukey com $(p \leq 0,05)$.

Para a safra 2014/15, aos 33 DAS, a densidade de semeadura de 450 mil sementes viáveis ha $^{-1}$ apresentou a maior porcentagem de cobertura do solo pelo dossel (Tabela 3), pela maior quantidade de plantas dispostas na área. Já aos 57 DAS, as densidades de 300 e 450 mil sementes viáveis $\mathrm{ha}^{-1}$ se igualaram e somente a densidade de 150 mil sementes viáveis ha ${ }^{-1}$ não alcançou a cobertura total do solo pelo dossel diferindo estatisticamente das demais densidades de plantas. Holtz et al. (2014) observaram diferenças no tempo de fechamento para os estandes de 160 e 240 mil plantas ha ${ }^{-1}$, sendo que a densidade de 160 mil plantas $\mathrm{ha}^{-1}$ obteve o 
fechamento do dossel com 61 DAS, enquanto a densidade de 240 mil plantas ha $^{-1}$ apresentou o fechamento do dossel com 57 DAS. A porcentagem da cobertura do solo pelo dossel apresentou efeito isolado de espaçamento em todas as avaliações na safra 2013/14. Aos 35 e 43 DAS, os espaçamentos reduzido $(20 \mathrm{~cm})$ e fileira dupla $(20 / 80 \mathrm{~cm})$ apresentaram os menores valores de porcentagem da cobertura do solo pelo dossel (Tabela 3). Para o espaçamento reduzido isso decorreu da menor quantidade de plantas na linha de semeadura e para o espaçamento em fileira dupla pela maior distância entre as fileiras duplas. Aos 43 e 49 DAS a porcentagem da cobertura do solo pelo dossel foi maior no espaçamento cruzado $(50 \times 50 \mathrm{~cm})$ pela disposição das plantas na área que ocuparam melhor o espaço disponível, não diferindo do espaçamento usual.

O espaçamento em fileira dupla $(20 / 80 \mathrm{~cm})$ apresentou a menor porcentagem da cobertura do dossel aos 33 e 57 DAS (Tabela 3) na safra 2014/15, já que o espaço entre uma fileira dupla e a fileira dupla adjacente é maior e, assim, as plantas não conseguiram fechar o dossel. Aos 33 DAS, os espaçamentos usual $(50 \mathrm{~cm})$ e cruzado $(50 \times 50 \mathrm{~cm})$ apresentaram uma menor porcentagem de cobertura do solo, pela maior distância entre as linhas de semeadura em relação ao espaçamento reduzido $(20 \mathrm{~cm})$, mas aos 57 DAS os espaçamentos já apresentaram uma maior similaridade entre os respectivos dosséis. Nos espaçamentos intermediários, há uma distribuição equidistante e espacial do sistema radicular e da parte aérea das plantas, favorecendo assim o melhor aproveitamento dos recursos do ambiente como água, luz e nutrientes (SILVA et al., 2013). Nessas condições as plantas apresentam um crescimento mais harmônico, não exigindo das plantas o alongamento do caule em busca de luminosidade de qualidade, atenuando desse modo, o acamamento e o subsequente autossombreamento.

As correlações entre o NDVI e a porcentagem de cobertura do solo pelas plantas de soja aos $27,33,35,43$, 49 e 57 DAS foram de 0,$82 ; \quad 0,77 ; \quad 0,86 ; \quad 0,83 ; \quad 0,77$ e 0,75 ; respectivamente, significativas com ( $p \leq 0,01)$. Isso indica que a cobertura do solo pelo dossel da soja pode ser estimada pelo NDVI, cuja avaliação é menos trabalhosa, porém exige o equipamento adequado para tal.

\section{CONCLUSÕES}

O NDVI e a porcentagem de cobertura do solo pelo dossel de cultivares modernas de soja, com tipo de crescimento indeterminado, são mais afetados pelos espaçamentos entre fileiras no início do ciclo de desenvolvimento, mas na fase de enchimento de grãos as diferenças são menores e apenas as fileiras duplas $(20 / 80 \mathrm{~cm})$ não apresentam pleno fechamento do dossel.

A menor densidade avaliada - 150 mil sementes viáveis ha $^{-1}$ - ocasiona menor NDVI e cobertura do dossel no início do ciclo em relação às maiores densidades, entretanto, no final do ciclo essa diferença se dissipa.

\section{REFERÊNCIAS}

BALBINOT JUNIOR, A. A.; PROCÓPIO, S. O.; DEBIASI, H.; FRANCHINI, J. C.; PANISON, F. Semeadura cruzada em cultivares de soja com tipo de crescimento determinado. Semina: Ciências Agrárias, v. 36, n. 3, p.1215-1226, 2015a. http://dx.doi.org/10.5433/1679-

0359.2015v36n3p1215

BALBINOT JUNIOR, A. A.; PROCÓPIO, S. O.; COSTA, J. M.; KOSINSKI, C. L.; PANISON, F.; DEBIASI, H.; FRANCHINI, J. C. Espaçamento reduzido e plantio cruzado associados a diferentes densidades de plantas em soja. Semina: Ciências Agrárias, v. 36, n. 5, p. 29752984, 2015b. http://dx.doi.org/10.5433/1679$\underline{0359.2015 v 36 n 5 p 2977}$

BALBINOT JUNIOR, A. A. PROCÓPIO, S.O., NEUMAIER, N.; FERREIRA, A.S.; WERNER, F.; DEBIASI, H.; FRANCHINI, J. C. Semeadura cruzada, espaçamento entre fileiras e densidade de semeadura influenciando o crescimento e a produtividade de duas cultivares de soja. Revista de Ciências Agroveterinárias, v.15, n.2, p.83-93, 2016.

http://dx.doi.org/10.5965/223811711522016083

HEIFFIG, L. S.; CÂMARA, G. M. S.; MARQUES, L. A.; PEDROSO, D. B.; PIEDADE, S. M. S. Fechamento e índice de área foliar da cultura da soja em diferentes arranjos espaciais. Bragantia, v.65, n.2, p. 285-295, 2006.

http://dx.doi.org/10.1590/S0006$\underline{87052006000200010}$

HOLTZ, V.; COUTO, R. F.; OLIVEIRA, D. G.; REIS, E. F. Deposição de calda de pulverização e produtividade da soja cultivada em diferentes 
arranjos espaciais. Ciência Rural, v. 44, n. 8, p.1371-1376, 2014. http://dx.doi.org/10.1590/0103-8478cr20130783

HUETE, A. R; DIDAN, K; MIURA, T; RODRIGUEZ, E.P.; GAO, X.; FERREIRA, L.G. Overview of the radiometric and biophysical performance of the MODIS vegetation index. Remote Sensing of Environment, v. 83, p. 195-213, 2002. https://doi.org/10.1016/S0034-4257(02)00096-2

PONZONI, F. J.; SHIMABUKURO, Y. E.; KUPLICH, T. $M$. Sensoriamento remoto no estudo da vegetação. São Paulo: Câmara Brasileira do Livro, 2012.

PROCÓPIO, S. O.; BALBINOT JUNIOR, A. A.; DEBIASI, H.; FRANCHINI, J. C.; PANISON, F. Plantio cruzado na cultura da soja utilizando uma cultivar de hábito de crescimento indeterminado. Revista de Ciências Agrárias, Belém, v.56, n. 4, p.319325, 2013. http://doi.editoracubo.com.br/10.4322/rca.2013 $\underline{048}$

RAMME, F. L. P.; LAMPARELLI, R. A. C.; ROCHA, J. V. Perfis temporais NDVI MODIS, na cana-soca, de maturação tardia. Engenharia Agrícola, v. 30 n. $\quad 3, \quad$ p. $4802-494, \quad 2010$. http://dx.doi.org/10.1590/S0100-

$\underline{69162010000300012}$

RODRIGUES, C. P.; FONTANA, D. C.; MORAES, O. L. L.; ROBERTI, D. R. NDVI e fluxo de $\mathrm{CO}_{2}$ em lavoura de soja no Rio Grande do Sul. Revista Brasileira de Meteorologia, v. 28, n. 1, p. 95104, $2013 . \quad$ https://doi.org/10.1590/S010277862013000100011

SILVA, W. B.; PETTER, F. A.; LIMA, L. B.; ANDRADE, F. R. Desenvolvimento inicial de Urochloa ruziziensis e desempenho agronômico da soja em diferentes arranjos espaciais no cerrado MatoGrossense. Bragantia, v. 72, n. 2, p. 146-153, 2013.

http://dx.doi.org/10.1590/S0006-

$\underline{87052013000200006}$

WERNER, F.; BALBINOT JUNIOR, A. A.; FERREIRA, A. S.; AGUIAR E SILVA, M. A.; DEBIASI, H.; FRANCHINI, J. C. Soybean growth affected by seeding rate and mineral nitrogen. Revista Brasileira de Engenharia Agrícola e Ambiental, v. 20, n.8, p.734-738, 2016. http://dx.doi.org/10.1590/18071929/agriambi.v20n8p734-738

Recebido para publicação em 12/01/2018 Revisado em 27/03/2018

Aceito em 29/06/2018 